Research Paper

\title{
Circulating Tumor Cells (CTC) Are Associated with Defects in Adaptive Immunity in Patients with Inflammatory Breast Cancer
}

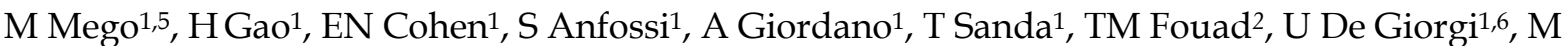 \\ Giuliano 1,7, WA Woodward 3, RH Alvarez 2,4,8, V Valero 2,4 , NT Ueno ${ }^{2,4}$, GN Hortobagyi2, M Cristofanilli2,,9 \\ and JM Reuben $1,4, \mathbb{}$
}

1. Department of Hematopathology, The University of Texas, MD Anderson Cancer Center, Houston, TX, USA;

2. Department of Breast Medical Oncology, The University of Texas, MD Anderson Cancer Center, Houston, TX, USA;

3. Department of Radiation Oncology, The University of Texas, MD Anderson Cancer Center, Houston, TX, USA;

4. Morgan Welch Inflammatory Breast Cancer Research Program and Clinic, The University of Texas, MD Anderson Cancer Center, Houston, TX, USA;

5. Currently at $2^{\text {nd }}$ Department of Oncology, Faculty of Medicine, Comenius University and National Cancer Institute, Bratislava, Slovakia;

6. Currently at Medical Oncology, Istituto Scientifico Romagnolo per lo Studio e la Cura dei Tumori (IRST) - IRCCS, Meldola (FC), Italy;

7. Currently at Department of Clinical Medicine and Surgery, University Federico II, Naples. Italy;

8. Currently at Cancer Treatment Centers of America, Newnan, GA, USA;

9. Currently at Thomas Jefferson University-Kimmel Cancer Center, Philadelphia, PA, USA.

$\triangle$ Corresponding author: Dr. J. M. Reuben, Department of Hematopathology, The University of Texas MD Anderson Cancer Center, 1515 Holcombe Blvd, Houston, TX 77030, USA. Tel: +1-713-745-6837; Fax: +1-713-794-1838; E-mail: jreuben@mdanderson.org.

(c) Ivyspring International Publisher. Reproduction is permitted for personal, noncommercial use, provided that the article is in whole, unmodified, and properly cited. See http://ivyspring.com/terms for terms and conditions.

Received: 2015.06.30; Accepted: 2015.09.07; Published: 2016.06.03

\begin{abstract}
Background: Circulating tumor cells (CTCs) play a crucial role in tumor dissemination and are prognostic in primary and metastatic breast cancer. Peripheral blood (PB) immune cells contribute to an unfavorable microenvironment for CTC survival. This study aimed to correlate CTCs with the PB T-cell immunophenotypes and functions of patients with inflammatory breast cancer (IBC).

Methods: This study included 65 IBC patients treated at the MD Anderson Cancer Center. PB was obtained from patients prior to starting a new line of chemotherapy for CTCs enumeration by CellSearch ${ }^{\circledR}$, and T cell phenotype and function by flow cytometry; the results were correlated with CTCs and clinical outcome.

Results: At least 1 CTC $(\geq 1)$ or $\geq 5$ CTCs was detected in $61.5 \%$ or $32.3 \%$ of patients, respectively. CTC count did not correlate with total lymphocytes; however, patients with $\geq 1$ CTC or $\geq 5$ CTCs had lower percentages (\%) of CD3+ and CD4+ T cells compared with patients with no CTCs or $<5$ CTCs, respectively. Patients with $\geq 1 \mathrm{CTC}$ had a lower percentage of T-cell receptor (TCR)-activated CD8+ T cells synthesizing TNF- $\alpha$ and IFN- $\gamma$ and a higher percentage of T-regulatory lymphocytes compared to patients without CTCs. In multivariate analysis, tumor grade and \% CD3+ T-cells were associated with $\geq 1$ CTC, whereas $\geq 5$ CTC was associated with tumor grade, stage, $\%$ CD3+ and \% CD4+ T cells, and \% TCR-activated CD8 T-cells synthesizing IL-17.

Conclusions: IBC patients with CTCs in PB had abnormalities in adaptive immunity that could potentially impact tumor cell dissemination and initiation of the metastatic cascade.
\end{abstract}

Key words: Circulating tumors cells, adaptive immunity, and inflammatory breast cancer

\section{Introduction}

Inflammatory breast cancer (IBC) is one of the most aggressive forms of breast cancer, and its incidence is approaching $5 \%$ of all breast cancers [1-3]. The prognosis of IBC patients remains poor with a 10-year disease-free survival rate of only $20-25 \%$, despite a multimodality treatment approach [4-9]. The disease is associated with resistance to standard therapies and early metastatic dissemination. These 
unsatisfactory results emphasize the need for a better understanding of the molecular aspects of this disease in order to improve outcome of IBC patients.

Metastatic disease is a major cause of death of breast cancer patients. The metastatic cascade consists of a series of biological steps that enables tumor cells to detach from the primary tumor, invade the blood venules to traverse the peripheral circulation, extravasate into the parenchyma and establish a new tumor [10]. Metastatic cascade is a highly inefficient process and only a minimal number of tumor cells that enter the blood circulation are capable of forming metastases [11-13]. Circulating tumor cells (CTCs) play a crucial role in metastatic cascade and are a prognostic factor in patients with primary [14] and metastatic breast cancer (MBC) [15]. Recently, we reported that CTCs can be detected in a large proportion of patients with newly diagnosed IBC and are a strong predictor of worse prognosis in patients with newly diagnosed IBC [16].

Peripheral blood (PB) represents a highly unfavorable microenvironment for the survival of CTCs owing to physical forces, the presence of immune cells, and anoikis, which collectively contribute to metastatic insufficiency $[17,18]$. More specifically, effective host innate and adaptive immune surveillance systems could adversely retard tumor dissemination whereas dysfunctional immune systems might provide a favorable microenvironment for the dissemination of CTCs and their survival in circulation, ultimately leading to cancer progression [19].

Current data concerning relationship between CTCs and the immune system in breast cancer are limited. Previous studies suggested, that MBC patients with $\geq 5$ CTCs per $7.5 \mathrm{~mL}$ of peripheral blood had significantly decreased natural killer (NK) cells function compared to patients with <5 CTCs [20]. Similarly, differences in expression of toll-like receptors (TLR) on immune cells were observed in MBC patients based on presence or absence of CTCs [21]. In non-metastatic breast cancer, patients with CTCs had a significant increase of peripheral CD95(FAS)-positive T-helper cells [22]. As the host immune response is regulated by CD95(APO-1/FAS)-CD95ligand interaction and apoptosis of cancer cells is induced via the CD95/CD95L pathway, it is supposed that this could lead to tumor cell escape by apoptotic T-helper cells [22].

$\mathrm{T}$ cells play a key role in the adaptive immune response. Thus, we hypothesize that patients with IBC with detectable CTCs exhibit deficits in adaptive immunity including a decrease in number and function of T-helper and cytotoxic T cells as well as an increase of immunosuppressive T-regulatory cells. The connection between CTCs and innate and adaptive immunity in patients with IBC has never been examined. In this translational study, we aimed to correlate CTCs with the status and functions of adaptive ( $\mathrm{T}$ cells) immune effector cells in $\mathrm{PB}$ of patients with IBC.

\section{Patients and Methods}

\section{Study patients}

The Institutional Review Board (IRB) of The University of Texas MD Anderson Cancer Center approved protocol LAB08-0199 (Chair, J. Reuben) to conduct this prospective translational study. A population of consecutive patients, who signed informed consent, with locally advanced or metastatic IBC treated from October 2008 through April 2012, was eligible. Patients underwent systemic therapy as appropriate for their malignancies, irrespective of the presence of CTCs or CTC count. Patients with a concurrent malignancy other than nonmelanoma skin cancer in the previous 5 years were excluded.

All patients underwent pretreatment diagnostic biopsy. The diagnosis of IBC was based on clinical signs such as diffuse erythema, peau d'orange, tenderness, induration, and warmth $[23,24]$. The presence of dermal lymphatic emboli in the diagnostic pathology report was not mandatory for the pathological diagnosis of IBC. Clinical stage at diagnosis of primary disease was coded according to the criteria set forth in the sixth edition of the American Joint Committee on Cancer's AJCC Cancer Staging Manual [25].

Data regarding age, tumor histologic subtype, hormone receptor status, HER2 amplification status, type and number of sites of metastasis, and delivery of systemic therapy were recorded in all the patients and compared with the presence and number of CTCs and immune cells profiling. Normal donors $(\mathrm{N}=34)$ were age-matched women without breast cancer who were recruited and consented according to the IRB-approved protocol.

\section{Detection of CTCs in peripheral blood}

The CellSearch system (Veridex Corporation, Warren, NJ) was used to detect and enumerate CTCs in $7.5 \mathrm{~mL}$ of whole peripheral blood. Samples were subjected to enrichment of epithelial cells with anti-EpCAM-coated ferrous particles. CTCs were defined as nucleated cells (DAPI+) lacking surface expression of the leukocyte antigen (CD45) and having cytoplasmic expression of cytokeratin 8,18 , or 19 [26]. Specimens were stored at room temperature and processed within 1 day of phlebotomy. CTCs 
were detected in patients before starting a new line of chemotherapy.

\section{Immune monitoring of patients}

From each patient, we obtained peripheral blood for the enumeration of CTCs and immune monitoring. All blood samples for CTCs as well as for immune cell analysis were collected at the same time before starting the new line of chemotherapy. Atraumatic venous blood sampling was performed at the antecubital fossa and patients provided $27 \mathrm{~mL}$ of peripheral blood for immune evaluation that included leukocyte immunophenotyping and cytokine syntheses by individual $T$ cells activated through the T-cell receptor (TCR) using immobilized anti-CD3 antibody and soluble anti-CD28 as costimulator, as previously described [27].

\section{T-cells subsets enumeration and cytokine synthesis by anti-CD3 activated $T$ cells}

Subsets of $\mathrm{T}$ cell subsets [CD4, CD8, and T-regulatory (Treg)] were determined by multi-parameter flow cytometry, as described previously [28]. Intracellular cytoplasmic syntheses of interleukin (IL)-2, IL-4, IL-10, IL-17, interferon-gamma (IFN- $\gamma)$, and tumor necrosis factor-alpha (TNF-a) by TCR-activated $\mathrm{T}$ cells were measured by a flow cytometric assay, as described previously $[27,29]$.

\section{Statistical analysis}

Patient characteristics were tabulated and summarized using the median (range) for continuous variables and frequency (percentage) for categorical variables. Normality of distribution was tested by the Kolmogorov-Smirnov test. If data were normally distributed, sample means were tested by Student $t$-test or analysis of variance. For non-normally distributed data, the nonparametric Mann-Whitney $U$ test or Kruskal-Wallis $H$ test was used. Pearson's or Spearman's correlation was used according to the normality of the data.

Baseline CTC count was defined as the earliest CTC measurement obtained before the start of a new line of therapy. We dichotomized baseline CTC counts using two different thresholds: as $<1$ or $\geq 1$ and as $<5$ or $\geq 5$ per $7.5 \mathrm{~mL}$ of peripheral blood. The cut-off at 1 CTCs was chosen because it has been investigated in other settings, such as in primary breast cancer, including locally advanced and inflammatory breast cancer $[14,16,30-34]$. The cut-off at 5 CTCs was shown to be prognostic for progression free survival (PFS) and overall survival (OS) in patients with metastatic breast cancer [15] as well as in IBC patients [16, 34].

Univariate analyses with Chi squared or the Fisher's exact test were performed to assess association between immune cells and CTC status followed by multivariate logistic regression analysis that included baseline CTC counts, immune cells, hormone receptor status (positive for either or negative for both), HER-2 status (overexpressed or negative), tumor grade (1 and 2 vs. 3 ), and tumor stage (stage III IBC vs. metastatic IBC), respectively. A backward model selection was conducted, and the final fitted model is shown in Tables 4 and 5 .

We correlated baseline CTC counts and different subpopulations of immune cells with OS. For survival analysis, immune cell percentages were dichotomized to "low" or "high" category using the median count of all study patients. Median follow-up period was calculated as a median observation time among all patients and among those still alive at the time of their last follow-up. OS was calculated from the date of baseline CTC enumeration to the date of death or last follow-up. OS was estimated using the Kaplan-Meier product-limit method and compared between groups using the log-rank test. A multivariate Cox proportional hazards model for OS was used to assess differences in outcome on the basis of baseline CTC counts, immune cells, hormone receptor status, HER-2 status, and tumor grade and stage. Step-wise regression techniques were used to build multivariate models using a significance level of 0.10 to remain in the model. All statistical tests were 2-sided, and $P$ values $<0.05$ were considered statistically significant.

\section{Results}

\section{Patients' characteristics}

This prospective study included 65 patients with IBC (21 stage III IBC, 14 de novo metastatic and 30 recurrent metastatic IBC) treated between October 2008 and April 2012 at the MD Anderson Cancer Center. Thirty-five $(53.9 \%)$ patients were treatment naïve at the time of blood collection. The median age of the study subjects was 54 years (range, 33-76 years). Fifty-eight (89.2\%) patients were of Caucasian origin. Patients' characteristics are shown in Table 1. Median baseline CTC count was 2 (range, $0-211$ ) per $7.5 \mathrm{~mL}$ of PB. Among the 65 patients with IBC, 40 patients $(61.5 \%)$ had a CTC count of $\geq 1$ and $21(32.3 \%) \geq 5$. The proportion of patients with IBC with $\geq 1$ CTC was lower in those with stage III than in metastatic (mIBC) IBC $(33.3 \%$ vs $75.0 \% ; P=0.002)$; the proportion of patients with stage III IBC with $\geq 5$ CTCs was also lower than for patients with $\mathrm{mIBC}(5.0 \%$ vs $45.5 \%$; $P=$ $0.001)$.

\section{T-cell subsets in IBC patients and normal donors}

Patients with IBC (stage III IBC plus mIBC) had a significantly lower absolute lymphocyte count (ALC) 
and percentage of lymphocytes than those of normal donors. The severe decrease in the ALC of patients was associated with stage of disease such that those with $\mathrm{mIBC}$ had a lower ALC than that of patients with stage III IBC (Table 2). Treatment naïve patients with mIBC had a non-significantly higher lymphocyte percentage compared to that of patients with pretreated $\mathrm{mIBC}(27.5 \pm 2.0$ vs. $21.4 \pm 1.8, \mathrm{p}=0.06)$, but still significantly lower compared to that of normal donors $(27.5 \pm 2.0$ vs. $32.7 \pm 1.4, \mathrm{p}=0.04)$. Additionally, lymphocyte immunophenotype analysis indicated that patients with stage III IBC had higher, while patients with $\mathrm{mIBC}$ had lower percentages of total $\mathrm{T}$ cells $(\mathrm{CD} 3+)$ and $\mathrm{CD} 3+\mathrm{CD} 4+$ (helper) T-cell subset, compared with those of healthy normal donors. Nevertheless, among the CD3+CD4+ T-cell subset, patients with $\mathrm{mIBC}$ had a higher percentage of T-regulatory lymphocytes than both patients with stage III IBC and healthy normal donors.

Twenty-four patients included in the study were HER2 positive, and $9(37.5 \%)$ of them were pretreated with trastuzumab-based chemotherapy. Trastuzumab is known to activate both the innate and the adaptive immune systems as well as to be capable of inducing long-lasting immune responses by reducing circulating $\mathrm{T}$ regulatory cells $[35,36]$. However, there was not a significant difference in any of the analyzed T-cell subsets in patients with $\mathrm{mIBC}$ based on previous treatment, except ALC, that was significantly higher in patients with prior to trastuzumab treatment in contrast to patients who were pretreated with chemotherapy without trastuzumab $(\mathrm{p}=0.04)$. Patients with prior trastuzumab treatment had significantly lower percentages of CD3+CD4+ T cells $(\mathrm{p}=0.01)$ and $\mathrm{CD} 3+\mathrm{CD} 8+\mathrm{T}$-cells that synthesized IFN- $\gamma(\mathrm{p}=0.03)$ and a higher percentage of $\mathrm{CD} 3+\mathrm{CD} 8+\mathrm{T}$ lymphocytes $(p=0.03)$, compared with patients who had received other chemotherapy agents or no therapy at all.

Table 1. Clinicopathological characteristics of patients with IBC $(n=65)$

\begin{tabular}{|c|c|c|c|c|}
\hline & \multicolumn{2}{|c|}{ Stage III IBC } & \multicolumn{2}{|c|}{ mIBC } \\
\hline & $\mathbf{N}$ & $\%$ & $\mathbf{N}$ & $\%$ \\
\hline All & 21 & 100.0 & 44 & 100.0 \\
\hline \multicolumn{5}{|l|}{ CTC per $7.5 \mathrm{~mL}$ of blood } \\
\hline$\geq 1$ & 7 & 33.3 & 33 & 75.0 \\
\hline$\geq 5$ & 1 & 4.8 & 22 & 50.0 \\
\hline \multicolumn{5}{|l|}{ Grade } \\
\hline 1 and 2 & 9 & 42.9 & 14 & 31.8 \\
\hline 3 & 12 & 57.1 & 29 & 65.9 \\
\hline unknown & 0 & 0.0 & 1 & 2.3 \\
\hline \multicolumn{5}{|l|}{ Histology } \\
\hline Invasive ductal carcinoma & 18 & 85.7 & 36 & 81.8 \\
\hline Other & 3 & 14.3 & 8 & 18.2 \\
\hline \multicolumn{5}{|l|}{ Hormone receptor status } \\
\hline Negative for both & 6 & 28.6 & 24 & 54.5 \\
\hline Positive for either & 15 & 71.4 & 20 & 45.5 \\
\hline \multicolumn{5}{|l|}{ HER2 status } \\
\hline Amplified & 10 & 47.6 & 14 & 31.8 \\
\hline Normal & 11 & 52.4 & 30 & 68.2 \\
\hline \multicolumn{5}{|l|}{ ER/PR and HER2/neu status } \\
\hline Triple receptor negative & 5 & 23.8 & 17 & 38.6 \\
\hline Non-triple receptor negative & 16 & 76.2 & 27 & 61.4 \\
\hline \multicolumn{5}{|l|}{ Sites of metastases } \\
\hline Non-visceral & NA & NA & 27 & 61.4 \\
\hline Visceral & NA & NA & 17 & 38.6 \\
\hline \multicolumn{5}{|l|}{ Bone metastases } \\
\hline Present & NA & NA & 23 & 52.3 \\
\hline Absent & NA & NA & 21 & 47.7 \\
\hline \multicolumn{5}{|l|}{ No. of metastasis } \\
\hline 1 & NA & NA & 21 & 47.7 \\
\hline$\geq 2$ & NA & NA & 23 & 52.3 \\
\hline \multicolumn{5}{|l|}{ Treatment } \\
\hline Treatment naïve & 21 & 100.0 & 14 & 31.8 \\
\hline Pretreated & 0 & 0.0 & 30 & 68.2 \\
\hline
\end{tabular}

Table 2. Association between IBC and different subpopulations of $T$ cells and their function

\begin{tabular}{|c|c|c|c|c|c|c|c|c|}
\hline Variable & $\mathrm{ND}(\mathrm{N}=34)$ & $\begin{array}{l}\text { IBC } \\
(\mathrm{N}=21)\end{array}$ & $\begin{array}{l}P- \\
\text { value } 1\end{array}$ & $\begin{array}{l}\mathrm{mIBC} \\
(\mathrm{N}=44)\end{array}$ & $\begin{array}{l}P- \\
\text { value }^{2}\end{array}$ & $\begin{array}{l}P- \\
\text { value }^{3}\end{array}$ & $\begin{array}{l}\text { All IBCa } \\
(\mathrm{N}=65)\end{array}$ & $\begin{array}{l}P- \\
\text { value } 4\end{array}$ \\
\hline White blood cells $\mathrm{k} / \mu \mathrm{L}$ & $6.9 \pm 0.4 b$ & $7.4 \pm 0.4$ & 0.10 & $6.7 \pm 0.4$ & 0.89 & 0.17 & $6.9 \pm 0.3$ & 0.55 \\
\hline Absolute lymphocytes count $\mathrm{k} / \mu \mathrm{L}$ & $2.2 \pm 0.1$ & $2.0 \pm 0.1$ & 0.31 & $1.5 \pm 0.1$ & $<0.001$ & 0.004 & $1.7 \pm 96.3$ & $<0.001$ \\
\hline Lymphocytes (\%) c & $32.6 \pm 1.5$ & $27.7 \pm 1.5$ & 0.01 & $23.3 \pm 1.3$ & $<0.001$ & 0.07 & $24.7 \pm 1.1$ & $<0.001$ \\
\hline CD3+ & $75.2 \pm 1.3$ & $80.3 \pm 1.4$ & 0.002 & $74.6 \pm 1.2$ & 0.73 & 0.01 & $76.4 \pm 1.0$ & 0.26 \\
\hline $\mathrm{CD} 3+\mathrm{CD} 4+$ & $47.7 \pm 1.7$ & $53.3 \pm 1.7$ & 0.01 & $44.6 \pm 1.5$ & 0.21 & 0.002 & $47.4 \pm 1.2$ & 0.88 \\
\hline $\mathrm{CD} 3+\mathrm{CD} 8+$ & $21.6 \pm 1.7$ & $21.4 \pm 1.6$ & 0.62 & $25.0 \pm 1.5$ & 0.46 & 0.23 & $23.8 \pm 1.2$ & 0.74 \\
\hline CD4/CD8 ratio & $2.5 \pm 0.3$ & $3.0 \pm 0.3$ & 0.24 & $2.4 \pm 0.2$ & 0.52 & 0.14 & $2.6 \pm 0.2$ & 0.98 \\
\hline Treg in CD4+ & $6.9 \pm 0.3$ & $6.6 \pm 0.4$ & 0.52 & $7.7 \pm 0.3$ & 0.04 & 0.03 & $7.3 \pm 0.2$ & 0.23 \\
\hline $\mathrm{CD} 3+\mathrm{CD} 4+\mathrm{IFN}-\gamma$ & $9.0 \pm 1.2$ & $12.6 \pm 1.3$ & 0.07 & $9.1 \pm 1.0$ & 0.95 & 0.06 & $10.3 \pm 0.8$ & 0.39 \\
\hline $\mathrm{CD} 3+\mathrm{CD} 4+\mathrm{TNF}-\alpha$ & $22.4 \pm 2.2$ & $24.4 \pm 2.4$ & 0.55 & $19.9 \pm 2.0$ & 0.20 & 0.19 & $21.4 \pm 1.6$ & 0.52 \\
\hline CD3+ CD4+ IL-2 & $15.1 \pm 1.8$ & $16.6 \pm 1.8$ & 0.62 & $14.0 \pm 1.7$ & 0.37 & 0.15 & $14.9 \pm 1.3$ & 0.68 \\
\hline $\mathrm{CD} 3+\mathrm{CD} 4+\mathrm{IL}-4$ & $2.9 \pm 0.3$ & $2.1 \pm 0.3$ & 0.04 & $2.2 \pm 0.3$ & 0.02 & 0.90 & $2.2 \pm 0.2$ & 0.01 \\
\hline CD3+ CD4+ IL-10 & $5.6 \pm 0.9$ & $6.1 \pm 1.0$ & 0.99 & $5.3 \pm 0.7$ & 0.57 & 0.81 & $5.6 \pm 0.6$ & 0.69 \\
\hline CD3+ CD4+ IL-17 & $2.8 \pm 0.3$ & $2.5 \pm 0.3$ & 0.41 & $2.7 \pm 0.3$ & 0.67 & 0.77 & $2.7 \pm 0.2$ & 0.50 \\
\hline
\end{tabular}




\begin{tabular}{|c|c|c|c|c|c|c|c|c|}
\hline $\mathrm{CD} 3+\mathrm{CD} 8+\mathrm{IFN}-\gamma$ & $11.2 \pm 1.6$ & $18.8 \pm 1.9$ & 0.01 & $10.3 \pm 1.2$ & 0.65 & 0.001 & $13.3 \pm 1.1$ & 0.37 \\
\hline $\mathrm{CD} 3+\mathrm{CD} 8+\mathrm{TNF}-\alpha$ & $12.6 \pm 1.7$ & $15.3 \pm 1.9$ & 0.27 & $10.2 \pm 1.4$ & 0.22 & 0.02 & $12.0 \pm 1.2$ & 0.70 \\
\hline CD3+ CD8+ IL-2 & $6.4 \pm 1.2$ & $7.3 \pm 1.3$ & 0.17 & $6.0 \pm 1.0$ & 0.71 & 0.14 & $6.4 \pm 0.8$ & 0.73 \\
\hline CD3+ CD8+IL-4 & $1.2 \pm 0.2$ & $1.4 \pm 0.3$ & 0.93 & $1.0 \pm 0.1$ & 0.31 & 0.48 & $1.1 \pm 0.1$ & 0.45 \\
\hline CD3+ CD8+IL-10 & $4.7 \pm 0.6$ & $4.8 \pm 0.8$ & 0.77 & $3.3 \pm 0.5$ & 0.01 & 0.11 & $3.8 \pm 0.4$ & 0.05 \\
\hline CD3+ CD8+IL-17 & $1.1 \pm 0.3$ & $2.0 \pm 0.3$ & 0.23 & $1.4 \pm 0.2$ & 0.64 & 0.40 & $1.6 \pm 0.2$ & 0.39 \\
\hline
\end{tabular}

Abbreviations: ND, normal donors; IBC, stage III inflammatory breast cancer; mIBC, metastatic IBC; a All IBC = IBC $+\mathrm{mIBC}$; ${ }^{\mathrm{b}} \mathrm{Mean} \pm \mathrm{SEM}$ (standard error of the mean); all immune cells data are presented as percentage except otherwise specified; ${ }^{1} \mathrm{ND}$ vs. IBC, ${ }^{2} \mathrm{ND}$ vs. $\mathrm{mIBC},{ }^{3} \mathrm{IBC}$ vs. $\mathrm{mIBC},{ }^{4} \mathrm{ND}$ vs. IBC $+\mathrm{mIBC}$

Table 3. Association between CTCs and different subpopulations of T-cells and their function

\begin{tabular}{|c|c|c|c|c|c|c|}
\hline Variable & $\begin{array}{l}\text { CTC }<1 \\
\text { Mean } \pm \text { SEM }\end{array}$ & $\begin{array}{l}\text { CTC } \geq 1 \\
\text { Mean } \pm \text { SEM }\end{array}$ & $P$ - value & $\begin{array}{l}\text { CTC }<5 \\
\text { Mean } \pm \text { SEM }\end{array}$ & $\begin{array}{l}C T C \geq 5 \\
\text { Mean } \pm \text { SEM }\end{array}$ & $P$ - value \\
\hline White blood cells $\mathrm{k} / \mathrm{uL}$ & $6.6 \pm 0.5$ & $7.1 \pm 0.38$ & 0.24 & $6.8 \pm 0.37$ & $7.1 \pm 0.53$ & 0.45 \\
\hline Absolute lymphocytes count $\mathrm{k} / \mu \mathrm{L}$ & $1.7 \pm 0.2$ & $1.7 \pm 0.1$ & 0.92 & $1.6 \pm 0.1$ & $1.8 \pm 0.2$ & 0.54 \\
\hline \%Lymphocytes * & $26.9 \pm 1.9$ & $22.3 \pm 1.5$ & 0.11 & $24.9 \pm 1.4$ & $24.3 \pm 2.1$ & 0.53 \\
\hline$\% \mathrm{CD} 3+$ & $80.2 \pm 1.6$ & $74.2 \pm 1.3$ & 0.01 & $78.3 \pm 1.2$ & $72.7 \pm 1.8$ & 0.004 \\
\hline $\mathrm{CD} 3+\mathrm{CD} 4+$ & $50.9 \pm 2.2$ & $45.3 \pm 1.7$ & 0.07 & $49.5 \pm 1.6$ & $43.3 \pm 2.3$ & 0.05 \\
\hline $\mathrm{CD} 3+\mathrm{CD} 8+$ & $24.3 \pm 2.4$ & $23.5 \pm 1.8$ & 0.42 & $23.6 \pm 1.8$ & $24.2 \pm 2.5$ & 0.96 \\
\hline CD4/CD8 ratio & $2.5 \pm 0.3$ & $2.6 \pm 0.3$ & 0.90 & $2.7 \pm 0.3$ & $2.3 \pm 0.4$ & 0.92 \\
\hline Treg in CD4+ & $6.8 \pm 0.4$ & $7.7 \pm 0.3$ & 0.05 & $7.1 \pm 0.3$ & $7.8 \pm 0.4$ & 0.15 \\
\hline $\mathrm{CD} 3+\mathrm{CD} 4+\mathrm{IFN}-\gamma$ & $11.0 \pm 1.4$ & $9.8 \pm 1.1$ & 0.51 & $10.8 \pm 1.1$ & $9.1 \pm 1.5$ & 0.50 \\
\hline $\mathrm{CD} 3+\mathrm{CD} 4+\mathrm{TNF}-\alpha$ & $23.2 \pm 2.5$ & $20.2 \pm 2.1$ & 0.40 & $22.1 \pm 2.0$ & $20.0 \pm 2.8$ & 0.58 \\
\hline CD3+ CD4+ IL-2 & $17.0 \pm 2.1$ & $13.5 \pm 1.7$ & 0.26 & $15.4 \pm 1.6$ & $14.0 \pm 2.3$ & 0.62 \\
\hline $\mathrm{CD} 3+\mathrm{CD} 4+\mathrm{IL}-4$ & $1.8 \pm 0.3$ & $2.4 \pm 0.3$ & 0.16 & $2.1 \pm 0.3$ & $2.3 \pm 0.4$ & 0.95 \\
\hline $\mathrm{CD} 3+\mathrm{CD} 4+\mathrm{IL}-10$ & $5.5 \pm 1.0$ & $5.6 \pm 0.8$ & 0.62 & $6.2 \pm 0.8$ & $4.4 \pm 1.1$ & 0.19 \\
\hline CD3+ CD4+ IL-17 & $2.4 \pm 0.3$ & $2.9 \pm 0.3$ & 0.16 & $2.5 \pm 0.3$ & $2.9 \pm 0.4$ & 0.20 \\
\hline $\mathrm{CD} 3+\mathrm{CD} 8+\mathrm{IFN}-\gamma$ & $16.2 \pm 1.8$ & $11.2 \pm 1.5$ & 0.08 & $13.6 \pm 12.6$ & $11.5 \pm 2.1$ & 0.87 \\
\hline $\mathrm{CD} 3+\mathrm{CD} 8+\mathrm{TNF}-\alpha$ & $14.9 \pm 1.8$ & $10.0 \pm 1.5$ & 0.03 & $12.3 \pm 1.4$ & $11.3 \pm 2.1$ & 0.65 \\
\hline CD3+ CD8+ IL-2 & $7.8 \pm 1.3$ & $5.5 \pm 1.0$ & 0.26 & $6.3 \pm 1.0$ & $6.7 \pm 1.4$ & 0.58 \\
\hline CD3+ CD8+IL-4 & $1.2 \pm 0.2$ & $1.1 \pm 0.2$ & 0.79 & $1.1 \pm 0.2$ & $1.1 \pm 0.2$ & 0.70 \\
\hline CD3+ CD8+IL-10 & $3.3 \pm 0.7$ & $4.2 \pm 0.6$ & 0.61 & $3.8 \pm 0.6$ & $3.8 \pm 0.8$ & 0.45 \\
\hline CD3+ CD8+IL-17 & $1.6 \pm 0.3$ & $1.6 \pm 0.3$ & 0.70 & $1.4 \pm 0.3$ & $2.0 \pm 0.4$ & 0.05 \\
\hline
\end{tabular}

Abbreviations: SEM, standard error of the mean; *all immune cell data are presented as percentage, except otherwise specified

\section{Ability of CD4+ and CD8+ T-cell subsets to synthesize cytokines}

CD4+ and CD8+ T-cell subsets were assessed for their ability to synthesize cytokines (IL-2, IL-4 IL-10, IL-17, IFN- $\gamma$ and TNF- $\alpha$ ) following activation through the TCR with immobilized anti-CD3 antibody and soluble anti-CD28 costimulatory factor. Both cohorts of patients with IBC (stage III IBC, $p=0.04$; and mIBC, $\mathrm{p}=0.02)$ had a lower percentage of TCR-activated CD4+ T-cells that synthesized IL-4 compared with those of normal donors. Whereas patients with stage III IBC had a higher percentage of TCR-activated CD8 $+\mathrm{T}$ cells that synthesized IFN- $\gamma$ than those of normal donors and those of patients with $\mathrm{mIBC}$, the percentage of TCR-activated CD8 $+\mathrm{T}$ cells that synthesized IL-10 was lower in patients with mIBC than in both healthy normal donors and patients with stage III IBC (Table 2).

\section{Association between CTCs and percentage of different $\mathbf{T}$ cell subsets}

There was no correlation between the CTC count and the absolute lymphocyte count; however, in contrast with patients without CTCs, patients with $\geq 1$ CTC had significantly lower percentages of CD3+ T cells and TCR-activated CD8+ T cells that synthesized TNF- $\alpha$ and IFN- $\gamma$, and a higher percentage of T-regulatory lymphocytes (Table 3). Further, in comparison with patients with $<5$ CTCs, patients with $\geq 5$ CTCs had lower percentages of CD3+ T cells and $\mathrm{CD} 3+\mathrm{CD} 4+\mathrm{T}$ cells, but a higher percentage of TCR-activated CD8+ $\mathrm{T}$ cells that synthesized IL-17. Patients with IBC with no CTCs had significantly lower absolute and relative lymphocyte counts, higher percentage of $\mathrm{CD} 3+\mathrm{T}$ cells and lower percentage of CD4+ $\mathrm{T}$ cells that synthesized IL-4, compared to those of healthy normal donors. In multivariate analysis, tumor grade and percentage of CD3+ T cells were associated with the presence of $\geq 1$ CTCs (Table 4), while tumor grade, tumor stage, and 
percentages of CD3+ T cells and TCR-activated CD8+ $T$ cell synthesizing IL- 17 were associated with the $\geq 5$ CTC status (Table 5).

\section{Prognostic value of CTC and T cell subsets in IBC}

At a median follow-up time of 19.4 months (range, 1.0-66.0 months), 42 patients (65.0\%) had died. Patients with either $\geq 1$ CTC or $\geq 5$ CTCs had a significantly inferior overall survival (OS) $[H R=2.48, p$ $=0.003$ and $\mathrm{HR}=1.85, \mathrm{p}=0.045]$ than patients with no CTCs or with $<5$ CTCs, respectively (Figure 1A). Patients with "low" ALC and "low" percentages of CD4+ $\mathrm{T}$ cells, TCR-activated CD4+ $\mathrm{T}$ cells synthesizing IL-2, and TCR-activated CD8+ T cells synthesizing IL-2, TNF- $\alpha$ and/or IFN- $\gamma$ had inferior survival than patients with "high" percentages of these cells (Table 6). In multivariate analysis, HER2 status, hormone receptor status, and TCR-activated CD8+ T cells synthesizing IFN- $\gamma$ were associated with overall survival, while CTCs had borderline significance $(p=0.059)$ (Table 7).

In subsequent analysis, we combined the prognostic value of CTCs and immune cells. Patients with $\geq 5$ CTCs and low percentages of all lymphocytes, CD3+CD4+ T cells and TCR-activated CD8+ T cells synthesizing IFN- $\gamma$ had significantly worse survival compared with that of patients with $<5$ CTCs and high percentages of these immune cells. For example, patients with "low" TCR-activated CD8+ T cells synthesizing IFN- $\gamma$ and $\geq 5$ CTC had significantly worse OS compared to patients with "high" TCR-activated CD8+ T cells synthesizing IFN- $\gamma$ and $<$ 5 CTC. $(\mathrm{HR}=3.60,95 \%$ CI $1.32-9.87, \mathrm{p}=0.008)$ (Figure 1B).

Table 4. Multivariate logistic regression model for the binary indicator of CTC $\geq 1$

\begin{tabular}{lllll}
\hline Variable & Odds ratio & $95 \%$ CI Low & 95\% CI Upper & $P$ - value \\
\hline $\begin{array}{l}\text { \% CD3+ } \\
\text { (continous variable) }\end{array}$ & 0.89 & 0.82 & 0.96 & 0.005 \\
$\begin{array}{l}\text { Grade } \\
3 \text { vs. 1 and 2 }\end{array}$ & 3.48 & 1.02 & 11.84 & 0.046 \\
\hline
\end{tabular}

Table 5. Multivariate logistic regression model for the binary indicator of CTC $\geq 5$

\begin{tabular}{|c|c|c|c|c|}
\hline Variable & Odds ratio & 95\% CI Low & 95\% CI Upper & $P$-value \\
\hline $\begin{array}{l}\text { \% CD3+ } \\
\text { (continous variable) }\end{array}$ & 0.89 & 0.79 & 1.00 & 0.046 \\
\hline $\begin{array}{l}\% \mathrm{CD} 3+\mathrm{CD} 4+ \\
\text { (continous variable) }\end{array}$ & 0.94 & 0.86 & 1.04 & 0.217 \\
\hline $\begin{array}{l}\text { \% CD3+ CD8+IL-17+ } \\
\text { (continous variable) }\end{array}$ & 2.44 & 1.10 & 5.38 & 0.028 \\
\hline $\begin{array}{l}\text { Grade } \\
3 \text { vs. } 1 \text { and } 2\end{array}$ & 14.60 & 1.42 & 150.27 & 0.024 \\
\hline $\begin{array}{l}\text { Stage } \\
\text { metastatic vs. stage III }\end{array}$ & 52.94 & 1.10 & 2549.24 & 0.045 \\
\hline
\end{tabular}

Table 6. Prognostic value of CTCs and different subpopulations of $T$ cells and their function on overall survival in IBC patients

\begin{tabular}{|c|c|c|c|c|}
\hline Variable & Hazard ratio & Low $95 \% \mathrm{CI}$ & Upper 95\% CI & $P$-value \\
\hline CTCs ( $\geq 1$ vs. 0$)$ & 2.84 & 1.54 & 5.23 & 0.003 \\
\hline CTCs $(\geq 5$ vs. $<5)$ & 1.85 & 0.94 & 3.67 & 0.05 \\
\hline $\begin{array}{l}\text { Absolute lymphocyte } \\
\text { count } \\
\text { k/ } / \mathrm{L} \text { (low vs. high)* }\end{array}$ & 2.04 & 1.1 & 3.79 & 0.02 \\
\hline CD3+ & 1.23 & 0.66 & 2.28 & 0.52 \\
\hline $\mathrm{CD} 3+\mathrm{CD} 4+$ & 2.19 & 1.16 & 4.11 & 0.01 \\
\hline $\mathrm{CD} 3+\mathrm{CD} 8+$ & 0.66 & 0.35 & 1.24 & 0.18 \\
\hline $\mathrm{CD} 4 / \mathrm{CD} 8$ ratio & 1.76 & 0.92 & 3.33 & 0.07 \\
\hline Treg in CD4+ & 0.66 & 0.36 & 1.23 & 0.19 \\
\hline $\mathrm{CD} 3+\mathrm{CD} 4+\mathrm{IFN}-\gamma$ & 1.48 & 0.75 & 2.94 & 0.26 \\
\hline $\mathrm{CD} 3+\mathrm{CD} 4+\mathrm{TNF}-\alpha$ & 1.69 & 0.85 & 3.36 & 0.13 \\
\hline $\mathrm{CD} 3+\mathrm{CD} 4+\mathrm{IL}-2$ & 2.12 & 1.06 & 4.24 & 0.03 \\
\hline CD3+ CD4+IL-4 & 1.08 & 0.55 & 2.13 & 0.83 \\
\hline CD3+ CD4+IL-10 & 0.92 & 0.46 & 1.82 & 0.81 \\
\hline CD3+ CD4+IL-17 & 0.88 & 0.45 & 1.75 & 0.72 \\
\hline $\mathrm{CD} 3+\mathrm{CD} 8+\mathrm{IFN}-\gamma$ & 2.38 & 1.18 & 4.79 & 0.01 \\
\hline $\mathrm{CD} 3+\mathrm{CD} 8+\mathrm{TNF}-\alpha$ & 3.59 & 1.76 & 7.32 & 0.0001 \\
\hline CD3+ CD8+IL-2 & 2.07 & 1.04 & 4.12 & 0.03 \\
\hline CD3+ CD8+IL-4 & 1.31 & 0.66 & 2.59 & 0.44 \\
\hline CD3+ CD8+IL-10 & 1.5 & 0.76 & 2.96 & 0.24 \\
\hline CD3+ CD8+IL-17 & 1.39 & 0.27 & 7.3 & 0.65 \\
\hline
\end{tabular}

Table 7. Multivariate analysis of prognostic factors associated with overall survival.

\begin{tabular}{lll}
\hline Variable & $\begin{array}{l}\text { HR } \\
(95 \% \text { C.I. })\end{array}$ & $P$ - value \\
\hline HER2 status & 0.219 & 0.001 \\
Overexpressed vs. negative & $(0.089-0.542)$ & \\
HR status & 0.415 & 0.040 \\
Positive for either vs. negative for both & $(0.180-0.960)$ & \\
CD3+ CD4+ & 0.494 & 0.075 \\
High vs. low & $(0.227-1.075)$ & \\
CD3+ CD8+ IFN- $\gamma$ & 0.433 & 0.032 \\
High vs. low & $(0.202-0.930)$ & \\
\hline
\end{tabular}

* all immune cells subpopulation were dichotomized as "low" or "high" based on median value of percentage of immunes cells in all patients. All hazard ratios are based on comparison of "low" vs. "high" groups.

$\mathrm{HR}=$ hazard ratio.

\section{Discussion}

This prospective translational study confirmed our recent report on the prognostic value of CTCs in patients with IBC. [16]. Moreover, here we show for the first time that patients with IBC with CTCs (at least $1 \mathrm{CTC} / 7.5 \mathrm{~mL}$ of peripheral blood) have abnormalities in adaptive immunity as suggested by the lower percentages of both $\mathrm{CD} 3+\mathrm{T}$ cells and CD3+CD4+ T-helper cells. We suggest that an inverse correlation between CD3+ $\mathrm{T}$ cells and CTCs is corresponding to impaired adaptive immunity in patients with detectable CTCs [14]. Importantly, this 
inverse correlation is consistent for both stage III and metastatic IBC, including patients with $\mathrm{mIBC}$ who were treatment naïve. In contrast with the study by Gruber et al. of non-metastatic, non-IBC patients, we also found an inverse correlation between CTCs and CD4+ T cells in patients with IBC [22].

In comparison to normal donors, all patients with IBC had a significantly lower ALC, which correlated with disease stage, with the lowest lymphocyte counts being observed in patients with mIBC who had received prior treatment; however, this could be partly due to the myelosuppresive effect of chemotherapy patients. Lymphocytes play an important role in antitumor immunity, and the ALC is associated with patients' outcome in several types of
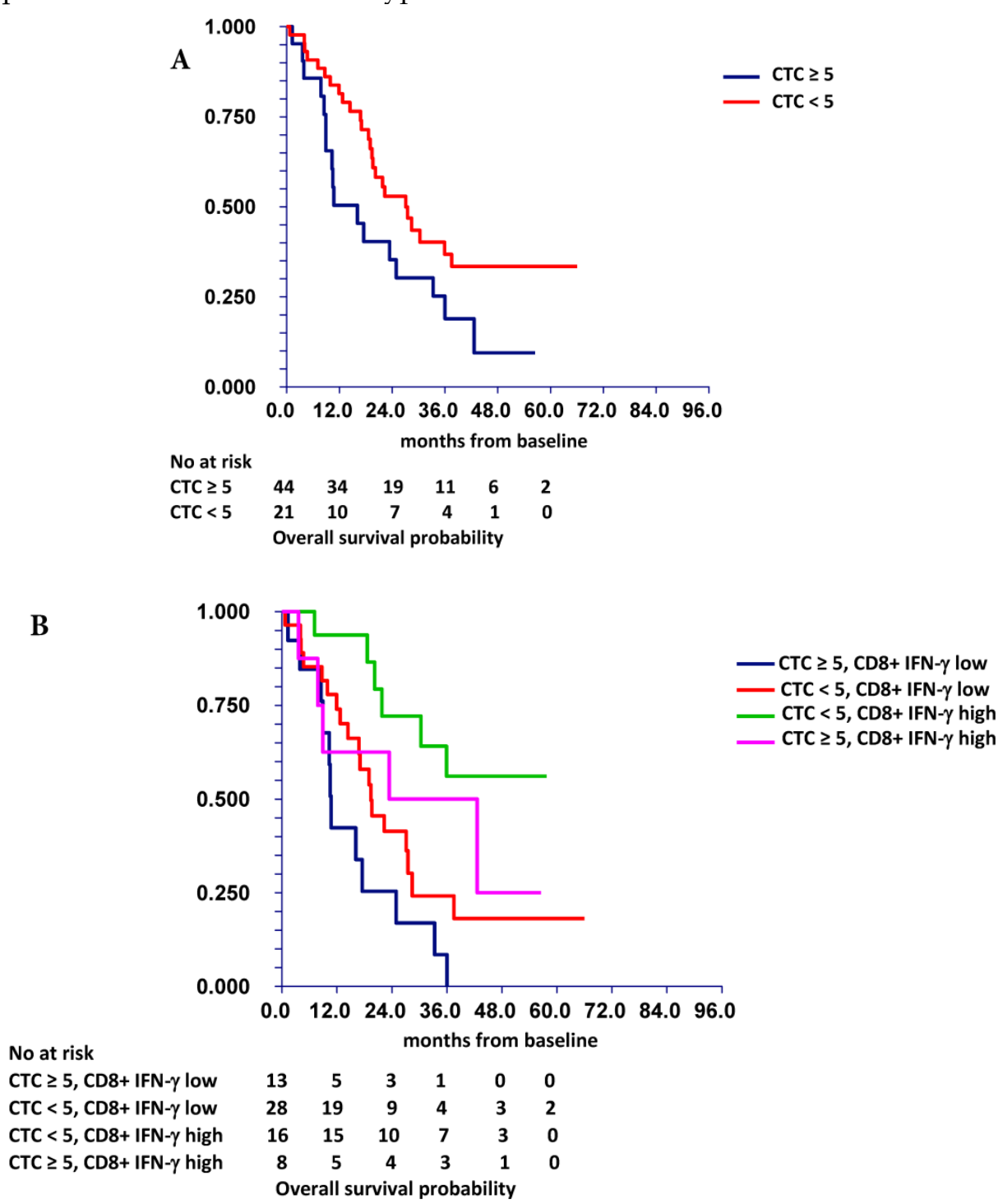

Figure 1. Prognostic value of CTC (A) and combined prognostic value of CTC and TCR-activated CD8+ T cells synthesizing IFN- $\gamma$ (B). Patients with "low" TCR-activated CD8+ T cells synthesizing IFN- $\gamma$ and CTC $\geq 5$ (group 3) had significantly worse survival (median OS = 10.5 months) compared to patients with "high" TCR-activated CD8+ T cells synthesizing IFN- $\gamma$ and CTC $<5$ (group 1) (median OS not reached). Patients with either "low" TCR-activated CD8+ T cells synthesizing IFN- $\gamma$ and CTC $<5$ (group 0 ) (median OS = 19.4 months) or "high" TCR-activated CD8+ T cells synthesizing IFN- $\gamma$ and CTC $\geq 5$ (group 4 ) (median OS $=24.9$ months) had intermediate prognosis. TCR-activated CD8+ T cells s synthesizing IFN- $\gamma$ were dichotomized as "low" or "high" based on median value of percentage of these cells in all patients. cancers including breast cancer [37-41]. In a previous study, we observed that patients with metastatic breast cancer with $<1000 / \mu \mathrm{L}$ lymphocytes have poorer prognosis compared to patients with a higher ALC and similar to this study, there was no association between peripheral blood lymphocytes and the number of CTCs [38]. In addition, we observed several other abnormalities in $\mathrm{T}$ cell numbers and their function in IBC patients, compared to normal donors (Table 2). Patients with $\mathrm{MIBC}$ had a higher percentage of T-regulatory cells compared to that of patients with stage III IBC as well as compared to that of normal donors, which is consistent with immunosuppression related to advanced stage of disease. 
In a further analysis of the CD4+ T-cell subsets in peripheral blood, we found that patients with mIBC had a higher proportion of T-regulatory cells than that of patients with stage III IBC. An increased T-regulatory cell frequency has been associated with advanced stages and poor prognosis in cancer patients [42]; however, this does not seem to be the case in breast cancer as patients with tumors overexpressing HER2 are believed to have a higher frequency of T-regulatory cells in peripheral blood, irrespective of stage of disease $[43,44]$. A more recent report showed that early breast cancer patients with HER2+ tumors were more likely to have an increased number of T-regulatory cells in peripheral blood compared with patients with HER2+ negative tumors [45] and that draining lymph nodes may also have a high frequency of these cells [46]. Collectively, these studies suggest that T-regulatory cells play a pivotal role in maintaining a pro-tumorigenic microenvironment [47] that might allow for the expansion of HER2+ CTCs. In our study, there was no correlation between expression of HER2+ in primary tumor and T-regulatory cells in peripheral blood; however, recent studies suggested that HER2+ amplification is present in CTCs from $15 \%$ to $30 \%$ in patients with HER2 negative primary tumor and from $60 \%$ to $98 \%$ in patients with HER 2 amplified primary tumor [48-50]. Therefore, we speculate that a positive correlation between CTCs and T-regulatory cells could reflect not only general dysfunction of adaptive immunity in patients with IBC who have poor prognosis disease, but also could be related to direct effect of T-regulatory cells that facilitate the dissemination of CTCs, thereby increasing their metastatic potential [51].

IL-17 is an inflammatory cytokine produced by CD4+ (Th17) and CD8+ (Tc17) T-cell subsets. Th17 cells are CD4+ $T$ cells that secrete IL-6, IL-17, and TNF- $\alpha$, and have been implicated in inflammation and autoimmune disease [52]. Tc1 cells are CD8+ T-cells that produce IFN- $\gamma$ and TNF- $\alpha$, and destroy their target cell through perforin or Fas-mediated pathways [53-55]. On the other hand, Tc17 cells express low levels of granzyme B, perforin and FasL and are incapable of destroying tumor cell targets cells [55]. In our study, patients with IBC who had $\geq 5$ CTCs had a higher percentage of TCR-activated CD8+ $\mathrm{T}$ cells that synthesized IL-17. While these cells show antitumor activity in vitro with potential implications for the CD8+ $\mathrm{T}$ cell-based adoptive immunotherapy [56], in patients with breast cancer the higher percentage of these cells correlated with disease progression [57], consistent with our results.

TCR-activated CD8+ T cells synthesizing IL-10 represents another suppressor T-cell lineage $[58,59]$, but surprisingly patients with $\mathrm{mIBC}$ had a significantly lower percentage of these cells than in both normal donors and in patients with stage III IBC. We speculate, that in patients with $\mathrm{mIBC}$, probably T-regulatory cells, but not TCR-activated CD8+ T cells synthesizing IL-10, represent the dominant pathway of immune tolerance. All patients with IBC (stage III IBC and $\mathrm{mIBC}$ ) had a lower percentage of TCR-activated CD4+ $\mathrm{T}$ cells that synthesized IL-4 compared to similar cells of normal donors, and this observation is consistent with a previous observation in patients with non-IBC breast cancer [60]. As IL-4 influences the activity of lymphokine activated killer (LAK) and natural killer (NK) cells [61-63], a lower percentage of TCR-activated CD4+ $\mathrm{T}$ cells synthesizing IL-4 could be reflective of a dysfunctional immune system in patients with breast cancer.

CTCs represent a heterogeneous population of cells with different phenotypes and biological value [18]. Experimental and clinical data suggest that the epithelial-to-mesenchymal transition (EMT) plays an important role in the generation of CTCs and the acquisition of resistance to therapy. Recent data showed that subpopulations of CTCs have partial or complete EMT phenotype [64-66]. EMT is closely linked to immunity and activation of the EMT program induces T-regulatory cells and impaired dendritic cells, suggesting that the immunosuppressive effect of EMT is consistent with our results of impaired adaptive immunity in patients with detectable CTCs [67].

Emerging data suggest the prognostic value of immune cells in different types of cancer, including breast cancer. Infiltration of tumor with different subpopulations of immune cells is closely associated with prognosis and/or response to anticancer treatment [68-70]. In our study, we observed the prognostic value of several lymphocyte subsets (Table 6) and more importantly, we achieved an increased prognostic value of CTCs in combination with immune cells (Figure 1). These data suggest that the properties of the microenvironment in cancer patients contribute to prognosis beyond CTCs in peripheral blood.

The main limitations of this study are sample size and patient population heterogeneity. To increase statistical power of analyses, we combined patients with stage III and metastatic IBC disease; however, we included disease stage in multivariate analyses to control for this confounder. Our results are applicable only to patients with IBC and similar studies in patients with non-IBC are warranted. Approximately half of the patients were pretreated with previous chemotherapy that could have affected study results 
as well, especially due to decreases in absolute lymphocyte counts associated with prior chemotherapy. To assess any relationship between CTCs and immune cells, we performed multiple comparisons; therefore, our results are only hypothesis generating, despite their biological and clinical rationale and should be confirmed in further studies.

In conclusion, in this study, we showed for the first time that patients with IBC with detectable CTCs had abnormalities in adaptive immunity. Based on these data, we suppose that observed associations between CTCs and T cells and their function could reflect results of direct interaction between CTCs and immune system in the peripheral blood. Alternatively, an increased CTC count could be a surrogate marker of more aggressive disease with an associated decrease in adaptive immunity and general dysfunction of immune system in inflammatory breast cancer. These data illustrate as well an inverse relationship between CTCs and adaptive immune cells in the peripheral blood microenvironment that could potentially impact tumor cell dissemination and initiation of the metastatic cascade. Moreover, immune cell profiling could add further prognostic value to CTCs in patients with inflammatory breast cancer.

\section{Acknowledgement}

We like to acknowledge Stephanie P. Demming for discussions and critical reading of the manuscript.

\section{Funding}

This work was supported by a grant from the State of Texas Rare and Aggressive Breast Cancer Research Program, which supports the MD Anderson Morgan Welch Inflammatory Breast Cancer Research Program and Clinic; a UICC American Cancer Society International Fellowship for Beginning Investigators Award [ACS/08/006 to M.M.]; a grant from the Slovak Grant Agency [VEGA 1/0044/15 to M.M.]; and a grant from the National Cancer Institute, National Institutes of Health [CA138239-02 to M.C., W.A.W., and J.M.R.].

\section{Competing Interests}

The authors have declared that no competing interest exists.

\section{References}

1. Anderson WF, Schairer C, Chen BE, Hance KW, Levine PH. Epidemiology of inflammatory breast cancer (IBC). Breast Dis 2005; 22.9-23

2. Hance KW, Anderson WF, Devesa SS, Young HA, Levine PH. Trends in inflammatory breast carcinoma incidence and survival: the surveillance, epidemiology, and end results program at the National Cancer Institute. J Natl Cancer Inst 2005; 97:966-975.

3. Walshe J, Swain S. Clinical aspects of inflammatory breast cancer. Breast Dis 2005; 22:35-4
4. Ueno NT, Buzdar AU, Singletary SE et al. Combined-modality treatment of inflammatory breast carcinoma: twenty years of experience at M.D. Anderson Cancer Center. Cancer Chemother Pharmacol 1997; 40:321-329.

5. Masuda H, Brewer TM, Liu DD et al. Long-term treatment efficacy in primary inflammatory breast cancer by hormonal receptor- and HER2-defined subtypes. Ann Oncol. 2014, 25:384-391.

6. Fouad TM, Kogawa T, Liu DD et al. Survival differences between patients with metastatic inflammatory and non-inflammatory breast cancer. Cancer Res 2013, 73 (24 Suppl): Abstract P6-12-02.

7. Cristofanilli M, Buzdar AU, Hortobagyi GN. Update on the management of inflammatory breast cancer. Oncologist 2003; 8:141-148.

8. Cristofanilli M, Valero V, Buzdar AU et al. Inflammatory breast cancer (IBC) and patterns of recurrence--understanding the biology of a unique disease. Cancer 2007; 110:1436-1444.

9. Robertson FM, Bondy $\mathrm{M}$, Yang $\mathrm{W}$ et al. Inflammatory breast cancer: the disease, the biology, the treatment. CA Cancer J Clin 2010; 60:351-375.

10. Fidler IJ. The pathogenesis of cancer metastasis: the 'seed and soil' hypothesis revisited. Nat Rev Cancer. 2003; 3:453-458.

11. Butler TP, Gullino PM. Quantitation of cell shedding into efferent blood of mammary adenocarcinoma. Cancer Res. 1975; 35:512-516.

12. Wong CW, Lee A, Shientag L et al. Apoptosis: an early event in metastatic inefficiency. Cancer Res. 2001; 61:333-338.

13. Baccelli I, Schneeweiss A, Riethdorf S et al. Identification of a population of blood circulating tumor cells from breast cancer patients that initiates metastasis in a xenograft assay. Nat Biotechnol. 2013; 31:539-544.

14. Lucci A, Hall CS, Lodhi AK et al. Circulating tumour cells in non-metastatic breast cancer: a prospective study. Lancet Oncol 2012; 13:688-695.

15. Cristofanilli M, Budd GT, Ellis MJ et al. Circulating tumor cells, disease progression, and survival in metastatic breast cancer. N Engl J Med 2004; 351:781-791.

16. Mego M, Giordano A, De Giorgi U et al. Circulating tumor cells in newly diagnosed inflammatory breast cancer. Breast Cancer Research 2015 (In press).

17. Zhan, M., Zhao, H. \& Han, Z. C. Signaling mechanisms of anoikis. Histol. Histopathol. 2004; 19:973-983.

18. Mego M, Mani SA, Cristofanilli M. Molecular mechanisms of metastasis in breast cancer--clinical applications. Nat Rev Clin Oncol. 2010; 7:693-701.

19. Hanahan D, Weinberg RA. Hallmarks of cancer: the next generation. Cell. 2011; 144:646-674.

20. Green TL, Cruse JM, Lewis RE, Craft BS. Circulating tumor cells (CTCs) from metastatic breast cancer patients linked to decreased immune function and response to treatment. Exp Mol Pathol. 2013; 95:174-179.

21. Green TL, Santos MF, Ejaeidi AA, Craft BS, Lewis RE, Cruse JM. Toll-like receptor (TLR) expression of immune system cells from metastatic breast cancer patients with circulating tumor cells. Exp Mol Pathol. 2014; 97: 44-48.

22. Gruber I, Landenberger $\mathrm{N}$, Staebler A, Hahn $\mathrm{M}$, Wallwiener $\mathrm{D}$, Fehm $\mathrm{T}$. Relationship between circulating tumor cells and peripheral T-cells in patients with primary breast cancer. Anticancer Res. 2013; 33:2233-2238.

23. Greene FL, Page DL, Fleming ID et al. AJCC Cancer Staging Handbook, 6th edition. New York, NY: Springer 2002.

24. Dawood S, Merajver SD, Viens $P$ et al. International expert panel on inflammatory breast cancer: consensus statement for standardized diagnosis and treatment. Ann Oncol 2011; 22:515-523.

25. Singletary SE, Allred C, Ashley P et al. Staging system for breast cancer: revisions for the 6th edition of the AJCC Cancer Staging Manual. Surg Clin North Am 2003; 83:803-819.

26. Allard WJ, Matera J, Miller MC et al. Tumor cells circulate in the peripheral blood of all major carcinomas but not in healthy subjects or patients with nonmalignant diseases. Clin Cancer Res. 2004; 10:6897-6904.

27. Naing A, Reuben JM, Camacho LH et al. Phase I Dose Escalation Study of Sodium Stibogluconate (SSG), a protein tyrosine phosphatase inhibitor, combined with interferon alpha for patients with solid tumors. J Cancer. 2011; 2:81-89.

28. Reuben JM, Lee BN, Li C et al. Biologic and immunomodulatory events after CTLA-4 blockade with ticilimumab in patients with advanced malignant melanoma. Cancer. 2006; 106:2437-2444.

29. Gao H, Lee BN, Talpaz M, Donato NJ, Cortes JE, Kantarjian HM, Reuben JM. Imatinib mesylate suppresses cytokine synthesis by activated CD4 T cells of patients with chronic myelogenous leukemia. Leukemia. 2005; 19:1905-1911.

30. Bidard FC, Mathiot C, Delaloge $S$ et al. Single circulating tumor cell detection and overall survival in nonmetastatic breast cancer. Ann Oncol 2010; 21:729-733.

31. Lang JE, Mosalpuria K, Cristofanilli M et al. HER2 status predicts the presence of circulating tumor cells in patients with operable breast cancer. Breast Cancer Res Treat 2009; 113:501-517.

32. Bidard F, Hajage D, Bachelot $T$ et al. Circulating tumor cells and CYFRA 21-1 as outcome-associated biomarkers in first line metastatic breast cancer: results of the IC 2006-04 study. Ann Oncol 2011; 22 (supplement 2): ii41-ii42.

33. Rack BK, Schindlbeck C, Andergassen $U$ et al. Use of circulating tumor cells (CTC) in peripheral blood of breast cancer patients before and after adjuvant chemotherapy to predict risk for relapse: the SUCCESS trial [abstract]. J Clin Oncol 2010; 28 (15 Suppl): a1003.

34. Mego M, De Giorgi U, Hsu L et al. Circulating tumor cells in metastatic inflammatory breast cancer. Ann Oncol 2009; 20:1824-1828.

35. Muraro E, Comaro E, Talamini R et al. Improved Natural Killer cell activity and retained anti-tumor $\mathrm{CD} 8(+) \mathrm{T}$ cell responses contribute to the induction of 
a pathological complete response in HER2-positive breast cancer patients undergoing neoadjuvant chemotherapy. J Transl Med. 2015; 13:204.

36. Datta J, Berk E, Xu S et al. Anti-HER2 CD4(+) T-helper type 1 response is a novel immune correlate to pathologic response following neoadjuvant therapy in HER2-positive breast cancer. Breast Cancer Res. 2015, 17:71.

37. De Giorgi $\mathrm{U}$, Rihawi $\mathrm{K}$, Aieta $\mathrm{M}$ et al. Lymphopenia and clinical outcome of elderly patients treated with sunitinib for metastatic renal cell cancer. J Geriatr Oncol. 2014; 5:156-163.

38. De Giorgi U, Mego M, Scarpi E et al. Relationship between lymphocytopenia and circulating tumor cells as prognostic factors for overall survival in metastatic breast cancer. Clin Breast Cancer. 2012; 12:264-269.

39. Fujiwara $\mathrm{Y}, \mathrm{Misawa} \mathrm{T}$, Shiba $\mathrm{H}$ et al. Postoperative peripheral absolute blood lymphocyte-to-monocyte ratio predicts therapeutic outcome after pancreatic resection in patients with pancreatic adenocarcinoma. Anticancer Res. 2014; 34:5163-5168.

40. Wei X, Huang F, Wei Y et al. Low lymphocyte-to-monocyte ratio predicts unfavorable prognosis in non-germinal center type diffuse large B-cell lymphoma. Leuk Res. 2014; 38:694-698.

41. Kobayashi N, Usui S, Kikuchi S et al. Preoperative lymphocyte count is an independent prognostic factor in node-negative non-small cell lung cancer. Lung Cancer. 2012; 75:223-227.

42. Knutson KL, Disis ML, Salazar LG. CD4 regulatory Tcells in human cancer pathogenesis. Cancer Immunol Immunother 2007; 56:271-285.

43. Perez SA1, Karamouzis MV, Skarlos DV et al. CD4+CD25+ regulatory T-cell frequency in HER-2/neu (HER)-positive and HER-negative advanced-stage breast cancer patients. Clin Cancer Res. 2007; 13:2714-2721.

44. Liyanage UK, Moore TT, Joo HG et al. Prevalence of regulatory T cells is increased in peripheral blood and tumor microenvironment of patients with pancreas or breast adenocarcinoma. J Immunol 2002; 169:2756 -2761.

45. Decker T, Fischer G, Bücke $W$ et al. Increased number of regulatory $T$ cells (T-regs) in the peripheral blood of patients with Her-2/neu-positive early breast cancer. J Cancer Res Clin Oncol. 2012; 138:1945-50.

46. Faghih Z, Erfani N, Haghshenas MR, Safaei A, Talei AR, Ghaderi A. Immune profiles of CD4+ lymphocyte subsets in breast cancer tumor draining lymph nodes. Immunology Letters 2014; 158:57-65.

47. Whiteside TL. Immune suppression in cancer: effects on immune cells, mechanisms and future therapeutic intervention. Semin Cancer Biol 2006; 16:3-15.

48. Fehm T, Müller V, Aktas B et al. HER2 status of circulating tumor cells in patients with metastatic breast cancer: a prospective, multicenter trial. Breast Cancer Res Treat. 2010; 124:403-412.

49. Punnoose EA, Atwal SK, Spoerke JM et al. Molecular biomarker analyses using circulating tumor cells. PLoS One. 2010; 5:e12517.

50. Flores LM, Kindelberger DW, Ligon $\mathrm{AH}$ et al. Improving the yield of circulating tumour cells facilitates molecular characterisation and recognition of discordant HER2 amplification in breast cancer. Br J Cancer. 2010; 102:1495-1502.

51. Sisirak V, Faget $\mathrm{J}$, Vey $\mathrm{N}$ et al. Plasmacytoid dendritic cells deficient in IFNa production promote the amplification of FOXP3 $(+)$ regulatory $\mathrm{T}$ cells and are associated with poor prognosis in breast cancer patients. Oncoimmunology. 2013; 2:e22338.

52. Mills KH. Induction, function and regulation of IL-17-producing T cells. Eur J Immunol. 2008; 38:2636-2649.

53. Dobrzanski MJ, Reome JB, Hollenbaugh JA, Dutton RW. Tc1 and Tc2 effector cell therapy elicit long-term tumor immunity by contrasting mechanisms that result in complementary endogenous type 1 antitumor responses. J Immunol. 2004; 172:1380-1390.

54. Vukmanovic-Stejic, M., B. Vyas, P. Gorak-Stolinska, A. Noble, D. M. Kemeny. 2000. Human Tc1 and Tc2/Tc0 CD8 T cell clones display distinct cell surface and functional phenotypes. Blood 2000; 95:231-240.

55. Yen HR, Harris TJ, Wada S et al. Tc17 CD8 T cells: functional plasticity and subset diversity. J Immunol. 2009; 183:7161-7168.

56. Hinrichs CS, Kaiser A, Paulos CM et al. Type $17 \mathrm{CD} 8+\mathrm{T}$ cells display enhanced antitumor immunity. Blood. 2009; 114:596-599.

57. Faghih Z, Rezaeifard S, Safaei A, Ghaderi A, Erfani N. IL-17 and IL-4 producing CD8 $+\mathrm{T}$ cells in tumor draining lymph nodes of breast cancer patients: positive association with tumor progression. Iran J Immunol. 2013; 10:193-204.

58. Zhao $Y$, Zhao H, Sun $Y$ et al. IL-4 induces a suppressive IL-10-producing CD8+ T cell population via a Cdkn2a-dependent mechanism. J Leukoc Biol. 2013; 94:1103-1112.

59. Noble A, Giorgini A, Leggat JA. Cytokine-induced IL-10-secreting CD8 T cells represent a phenotypically distinct suppressor T-cell lineage. Blood. 2006; 107:4475-4483

60. Campbell MJ, Scott J, Maecker HT, Park JW, Esserman LJ. Immune dysfunction anmicrometastases in women with breast cancer. Breast Cancer Res Treat. 2005; 91:163-171.

61. Naume B, Gately MK, Desai BB, Sundan A, Espevik T. Synergistic effects of interleukin 4 and interleukin 12 on NK cell proliferation. Cytokine. 1993; 5:38-46.

62. Brown MA, Hural J. Functions of IL-4 and control of its expression. Crit Rev Immunol. 1997; 17:1-32.

63. Swisher SG, Economou JS, Holmes EC, Golub SH. TNF-alpha and IFN-gamma reverse IL-4 inhibition of lymphokine-activated killer cell function. Cell Immunol. 1990; 128:450-461.
64. Yu M, Bardia A, Wittner BS et al Circulating breast tumor cells exhibit dynamic changes in epithelial and mesenchymal composition. Science 2013; 339:580-584.

65. Mego M, Mani SA, Lee BN et al. Expression of epithelial-mesenchymal transition-inducing transcription factors in primary breast cancer: the effect of neoadjuvant therapy. Int J Cancer 2012; 130:808-816.

66. Giordano A, Gao H, Anfossi $\mathrm{S}$ et al. Epithelial-mesenchymal transition and stem cell markers in patients with HER2-positive metastatic breast cancer. Mol Cancer Ther. 2012; 11:2526-2534

67. Kudo-Saito C, Shirako H, Takeuchi T, Kawakami Y. Cancer metastasis is accelerated through immunosuppression during Snail-induced EMT of cancer cells. Cancer Cell. 2009; 15:195-206.

68. Gu-Trantien C, Loi S, Garaud S et al. $\mathrm{CD}^{+}$follicular helper T cell infiltration predicts breast cancer survival. J Clin Invest. 2013; 123:2873-2892.

69. Loi S, Michiels S, Salgado R et al. Tumor infiltrating lymphocytes are prognostic in triple negative breast cancer and predictive for trastuzumab benefit in early breast cancer: results from the FinHER trial. Ann Oncol. 2014; 25:1544-1550.

70. Loi S, Sirtaine N, Piette F et al. Prognostic and predictive value of tumor-infiltrating lymphocytes in a phase III randomized adjuvant breast cancer trial in node-positive breast cancer comparing the addition of docetaxel to doxorubicin with doxorubicin-based chemotherapy: BIG 02-98. J Clin Oncol. 2013; 31:860-867. 